\title{
A instituição dos conselhos: participação e controle social, ou a "patologia" da representatividade?
}

\author{
Edite Maria Sudbrack* \\ Hildegard Susana Jung ${ }^{* *}$ \\ Mariana Balestrin ${ }^{* * *}$
}

\section{Resumo}

Este ensaio, de caráter teórico, visa investigar a atuação dos conselhos escolares e conselhos de alimentação nos municípios brasileiros, que surgem para oportunizar aos cidadãos a integração e a participação no processo de planejamento, formulação e controle das políticas públicas, propiciando a alocação mais justa e eficiente dos recursos públicos. Para tanto, analisamos a construção do processo democrático no Brasil, e a caminhada da participação popular nestes órgãos. Destaca o município de Frederico Westphalen, Rio Grande do Sul e estudo realizado no estado da Paraíba (NÓBREGA, 2011), traçando possibilidades e desafios para a participação, ainda que por meio do sistema representativo. Percebemos grandes dilemas enfrentados pelos conselhos que dificultam sua atuação como esfera de participação social, já que muitos esbarram na burocracia e na falta de conhecimento de sua missão por parte de seus componentes. Apesar de escasso o número de investigações a respeito, pode-se concluir que é necessário estreitar a relação entre teoria e prática para que os conselhos escolares e de alimentação consigam cumprir seu papel e, efetivamente, levar a comunidade para dentro da escola.

Palavras-chave: Democracia. Participação. Representatividade. Conselhos Escolares. Conselhos de Alimentação.

Mestre e doutora em Educação pela Ufrgs. Coordenadora e docente do Mestrado em Educação e professora do Curso de Pedagogia do Departamento de Ciências Humanas da Universidade Regional Integrada do Alto Uruguai e das Missões, Campus Frederico Westphalen. E-mail: sudbrack@uri.edu.br

** Psicopedagoga. Mestranda do PPGEdu da Universidade Regional Integrada do Alto Uruguai e das Missões - URI / Campus Frederico Westphalen - Bolsista Prosup - Capes. Integrante do Grupo de Pesquisa em Educação - GPE/URI/ FW. E-mail: hildegardsjung@gmail.com

*** Nutricionista. Mestranda do PPGEdu da Universidade Regional Integrada do Alto Uruguai e das Missões - URI / Campus Frederico Westphalen. E-mail: mari_dalmolin@hotmail.com 


\section{Considerações iniciais}

No Brasil, em uma perspectiva histórica do processo de descentralização das políticas públicas, a Constituição de 1988 emerge como marco do Estado democrático de direito, decorrente, sobretudo, dos princípios constitucionais que zelam pela participação da sociedade na formulação e na implementação de políticas públicas. A partir desse regulamento, os conselhos são criados (ainda que já houvessem movimentos anteriores neste sentido) e configuram um novo espaço de participação da sociedade em relação ao Estado, ao proporcionar o acesso da população às instâncias decisórias, ainda que em um sistema representativo, no qual certos cidadãos são imbuídos da responsabilidade de representar aos demais naquela instância de decisões.

Passados vinte e seis anos desde o (recente) início do processo de democratização impulsionado pela Constituição de 1988, propõe-se a reflexão sobre o momento que vive o país, sob a perspectiva da gestão democrática por intermédio das instituições conselhos, detendo-nos aos conselhos escolares e aos de alimentação, especificamente.

Para tanto, dividimos este ensaio, de cunho teórico e bibliográfico, incluindo aqui a análise de legislação vigente, em três partes. Num primeiro momento, buscamos alguns conceitos e reflexões acerca do termo democracia e da sua modalidade representativa. Na sequência, abordamos a questão da participação e do controle social, tendo como pano de fundo a constituição e funcionamento dos Conselhos de Educação e dos Conselhos de Alimentação Escolar (CAE), como instrumentos de controle social (local) e de participação democrática. Por fim, no terceiro momento, refletimos sobre as possibilidades e os desafios de um conselho que pretenda ser realmente efetivo, participativo e ativo dentro da escola ou da comunidade, levando em conta as especificidades e necessidades da sua região e como verdadeiro instrumento de participação, ainda que por meio do sistema de representatividade. Para tanto, registramos o caso do município de Frederico Westphalen, situado na região sul do Brasil e a pesquisa desenvolvida por Nóbrega (2011), junto a um conselho escolar no estado da Paraíba.

O conselho escolar é de fato uma oportunidade de participação efetiva, podendo levar a voz de toda a comunidade para dentro da escola? Está o cidadão brasileiro preparado para assumir este papel? A sociedade civil está sendo incentivada a participar, ou sofre, como referem Santos e Avitzer (2002, p. 42) da "patologia da representação"? Como podemos qualificar a representatividade dos conselhos? Diante desses questionamentos, nota-se a relevância da criação de canais legítimos de participação social, que promovam um ambiente democrático e permitam, de 
fato, a participação cidadã na formulação e gestão de políticas públicas. E, consequentemente, atue como mecanismos de controle público sobre as ações do Estado.

\section{Democracia e representatividade}

Democracia se refere primariamente a "a um conjunto de regras de procedimento para a formação de decisões coletivas, em que está prevista a participação mais ampla possível dos interessados" (BOBBIO, 1986, p. 12, grifo nosso), denotando já algum tipo de exclusão, visto que não é possível dizer que todos participam. $O$ autor italiano completa, alertando que, na democracia representativa, mesmo que todos os cidadãos votem, alguma faixa etária estaria excluída.

Etimologicamente, o termo democracia provém do grego antigo dēmokratía ou governo do povo, originando-se a partir de demos ou povo e kratos ou poder, no século V a.C. para nomear o sistema político adotado em cidades-Estados gregas, especialmente Atenas. Parece que a contradição acompanhou desde sempre esse conceito que, enquanto sistema de governo grego, curiosamente, excluía mulheres, estrangeiros e escravos (sim, era uma "democracia escravagista"!) que não tinham o direito de participar das decisões políticas da cidade "democrática". Em contrapartida, Fávero e Tonietto referem que "não podemos nos esquecer de que estamos nos referindo ao Século V a.C. e que há todo um contexto a ser considerado" (2012, p. 182.).

Segundo Santos e Avritzer (2002), o século XX foi um período de intensa disputa em torno da questão democrática, principalmente ao final das duas grandes guerras mundiais e ao longo de todo o período da Guerra Fria, articulando-se entre dois debates. O primeiro circulou em torno do desejo de democracia e o segundo questionou as formas estruturais da democracia, incluindo-se aqui a incompatibilidade entre a democracia e o capitalismo. Esta tensão "uma vez resolvida a favor da democracia, colocaria limites à propriedade e implicaria em ganhos distributivos para os setores sociais mais desfavorecidos" (SANTOS; AVRITZER, 2002, p. 40). Assim, as políticas públicas têm um papel fundamental no sentido de equilibrar a tensão entre o capital e o trabalho.

Hegemonicamente, a representatividade tornou-se o caminho 'natural' a ser seguido, uma vez que, no pós-guerra, os governos trabalharam no sentido de um procedimento eleitoral para constituir-se. Nesse sistema, segundo Bobbio (1986), os partidos políticos são as únicas instituições autorizadas a funcionar como elo entre o governo e o indivíduo, pois a própria democracia induz mais à representatividade do que à participação. $\mathrm{O}$ autor continua, referindo que a democracia representativa já é "por si mesma uma renúncia ao princípio da liberdade como autonomia” (1986, 
p. 26). Nesse mesmo viés, Santos e Avritzer (2002) corroboram, referindo que a representatividade segue o princípio de que o cidadão comum não tem capacidade de política, senão de escolher os líderes ao quais cabe tomar essas decisões. Os três autores ainda se colocam de acordo quando referem que a representatividade gera uma 'apatia' por parte do cidadão. Bobbio a menciona como "apatia eleitoral" e Santos e Avritzer (2002, p. 41) como "apatia política”, estes últimos arguindo que existe uma valorização desta apatia de parte dos partidos políticos no sentido que a população não interfira, fenômeno que acabaria gerando a "patologia da representação, o fato de que os cidadãos se consideram cada vez menos representados por aqueles que elegeram" (SANTOS; AVRITZER, 2002, p. 42).

No Brasil, onde a democracia é ainda recente, a abertura foi acontecendo lentamente, a partir dos anos 1980. Sempre coube à metrópole, e depois ao Estado decidir, por meios legais e jurídicos, a vida dos cidadãos, em especial, sua relação social. A Constituição de 1946 mostrou indícios de maior participação popular e acesso equitativo à educação até o golpe militar de 1964, que silenciou qualquer tentativa de participação popular. A política foi traçada com base no modelo econômico desenvolvimentista não nacionalista, nos termos de Furtado (1979), e anticomunista, o que se traduziu, na escola, em uma educação tecnicista, voltada a preparar jovens para o mercado de trabalho.

A evolução do processo democrático e das políticas públicas brasileiras, timidamente, tomaram corpo nos anos 1980, gerando grandes movimentos populares na conquista de um alicerce jurídico que resultou na atual Constituição Federal de 1988 (também conhecida como "Carta Cidadã"). A Constituição Federal passou a garantir uma sociedade livre, justa e solidária com erradicação da pobreza e da marginalização, bem como com a redução das desigualdades sociais e regionais. No campo educacional, não só garantiu a manutenção de escolas públicas como preconizou a gestão democrática.

\section{Participação e controle social}

Como antes referimos, no Brasil, as reivindicações da população no sentido de maior participação foram legitimadas com a Constituição de 1988, em que foi implantado um novo processo democrático e, então, a ordem "dominante" se rompe, dissolvendo a hegemonia do poder das elites. Os princípios nesta Constituição estabelecem a participação política e manifestam a intervenção direta da sociedade em atividades públicas, concretizando a abertura do espaço democrático de direito.

Nesse plano, percebe-se a necessidade da participação social para o exercício da cidadania, um dos princípios gerais da Carta Magna, que previu instrumentos 
concretos para o exercício da democracia participativa. Assim, a participação da sociedade civil organizada é fundamental para o controle, a fiscalização, o acompanhamento e a implantação das políticas públicas e, também, para o exercício da cidadania.

Para Gadotti (2013), a participação popular é inerente à noção de democracia, constituindo-se como um pressuposto da cidadania. A Constituição Federal de 1988 possibilitou a instituição da participação popular, porém, sua efetiva implantação está condicionada a mecanismos apropriados para o seu exercício. Torna-se necessário, então, o fornecimento de informações aos cidadãos, necessários para a defesa dos direitos e a participação na conquista de novos horizontes. Numa visão transformadora, a participação popular objetiva a construção de uma nova sociedade, mais justa e solidária. Cabe então definir brevemente os diferentes significados que compõem a expressão participação política:

[...] o termo participação se acomoda também a diferentes interpretações, já que se pode participar, ou tomar parte nalguma coisa, de modo bem diferente, desde a condição de simples espectador mais ou menos marginal à de protagonista de destaque (BOBBIO; MATTEUCCI; PASQUINO, 1998, p. 888).

Portanto, percebemos que a participação política efetiva não se concretiza com a simples presença na sociedade, mas, sim, com as lutas, reivindicações e mobilizações sociais. Para Bava (2005) a mudança não vem só pela afirmação dos novos espaços públicos de disputa, ou pela presença no Parlamento. A mudança vem desde que a sociedade seja capaz de se mobilizar e garantir que nesses espaços passem as decisões sobre as políticas públicas, transitem as decisões sobre os recursos públicos, sobre as estratégias que vão orientar a ação do Estado. Nessa perspectiva, Faundez (1993) exprime a importância da participação social:

Participação na criação do conhecimento, de um novo conhecimento, participação na determinação das necessidades essenciais da comunidade, participação na busca de soluções e, sobretudo, na transformação da realidade. Participação de todos aqueles que tomam parte no processo de educação e de desenvolvimento (FAUNDEZ, 1993, p. 32).

Os conselhos surgem como ferramentas que oportunizam a integração e a participação no planejamento, na formulação e no controle das políticas públicas, materializando a participação da sociedade nos processos decisórios e proporcionando a alocação mais justa dos recursos públicos. A participação em conselhos municipais, assim como o voto popular, são processos de democratização. Neste sentido, a descentralização exige modificação nos núcleos de poder que leva a uma maior distribuição de poder decisório até então centralizada nas mãos de poucos. Por meio da descentralização, pode-se aproximar a sociedade civil do Estado, diminuindo, assim, a distância que, historicamente, os separa. 
Nessa mesma perspectiva, Gadotti (2013) observa que o princípio da gestão democrática não deve ser percebido apenas como prática participativa e descentralização do poder, mas como radicalização da democracia, ao superar o autoritarismo, o patrimonialismo, o individualismo e as desigualdades sociais.

Para que a descentralização possa romper com o padrão autoritário do Estado, é preciso que esse abra suas portas à participação da população organizada. Logo, em se tratando do Programa Nacional de Alimentação Escolar, a formação dos CAE pode ser uma forma efetiva da gestão democrática, possibilitando a participação da comunidade na fiscalização dos recursos financeiros, na elaboração de projetos e na deliberação, diante das necessidades no conjunto da vida coletiva. De forma análoga, a participação nos Conselhos Escolares se apresenta imprescindível, o que buscaremos argumentar no decorrer deste ensaio.

Relacionados a um extenso leque de políticas e programas, como as políticas setoriais de saúde e educação, as políticas transversais de direitos humanos, e iniciativas mais específicas, como Alimentação Escolar, os conselhos se configuram como um novo espaço de participação da sociedade em sua relação com o Estado, ao propiciar o acesso da população e dos movimentos sociais às instâncias decisórias (GOMES, 2003). Assim, os conselhos gestores surgem como uma inovação ao reordenar as políticas públicas de maneira democrática. Cumpre destacar, mesmo que brevemente, a menção de Gohn (2011), a qual refere que os conselhos gestores diferem dos conselhos comunitários populares na medida em que

[...] conselhos comunitários populares ou dos novos fóruns civis não governamentais [...] são compostos exclusivamente de representantes da sociedade civil, cujo poder reside na força da mobilização e da pressão e, usualmente, não possuem assento institucionalizado junto ao poder público. Os conselhos gestores são diferentes também dos conselhos de "notáveis" existentes de algumas áreas do governo - como educação, saúde, etc. - pelo fato de eles serem formas de assessoria especializadas e incidirem na gestão pública de forma indireta. (GOHN, 2011, p. 89).

Destacamos, diante dessas considerações, que os conselhos gestores também estão vinculados ao repasse dos recursos do governo, sendo uma condicionalidade para que as políticas públicas possam se efetivar. A lei federal estabelece que a transferência e o recebimento dos recursos financeiros pelos municípios estão vinculados à existência de conselhos. Sob essa óptica, como já é sabido, os conselhos municipais são criados por leis locais, porém, suas regulamentações ficam a cargo estadual e federal. Com essas palavras, percebemos que o município não tem total liberdade para legislar, o que constitui uma autonomia limitada de estados e municípios no exercício do poder local. Um exemplo prático dessa apropriação do poder federal são os Conselhos Municipais de Alimentação Escolar (Comaes), hoje intitulado como CAE: 
O governo federal, por meio do Fundo Nacional de Desenvolvimento da Educação (FNDE), promulgou medida provisória dando prazo até 2 de setembro para que todos os municípios brasileiros criassem os Comaes [...] com a pressão governamental, por meio da mídia, ameaçando a suspensão do envio de verba para a merenda escolar, houve uma corrida para a formação dos conselhos, caracterizando um processo de participação outorgado, não fruto de um processo de cidadania ativa (GOHN, 2011, p. 107).

Retomando nossa análise, podemos perceber que o controle social na aplicação dos recursos públicos colocados à disposição do Estado é um fator extremamente importante na efetivação das políticas públicas. No Brasil, a expressão controle social tem sido utilizada como sinônimo de controle da sociedade civil sobre as ações do Estado, especificamente no campo das políticas sociais, desde o período da redemocratização dos anos de 1980. A utilização da expressão com esse sentido foi propiciada pela conjuntura de lutas políticas pela democratização do país frente ao Estado autoritário, implantado a partir da ditadura militar (BRAVO; CORREIA, 2012, p. 127). O controle social vincula-se a recursos materiais e simbólicos de que uma sociedade dispõe para assegurar a estabilidade social de seus membros mediante normatização da Constituição Federal. Logo, a sociedade se autorregula sem o uso de força (PEDRINI; ADAMS; SILVA, 2007).

Nessa perspectiva, o PNAE é uma política pública que tem como um dos princípios, regulamentado pela Resolução no 38, de 16 de julho de 2009, "VII - a participação da comunidade no controle social, no acompanhamento das ações realizadas pelos Estados, Distrito Federal e Municípios para garantir a execução do Programa" (Brasil, 2009).

Como já mencionado, o cumprimento desse inciso se faz por meio dos CAE, canais de controle direto da sociedade, materializando os princípios da democracia representativa e participativa. O CAE é um órgão deliberativo, fiscalizador e de assessoramento, instituído no âmbito dos estados, Distrito Federal e municípios, criado para acompanhar a utilização dos recursos financeiros transferidos pelo Fundo Nacional de Educação (FNDE) às Entidades Executoras, bem como zelar pela qualidade da alimentação escolar.

Vale ressaltar que o CAE pode representar um elemento essencial para assegurar que o governo atinja seus objetivos estabelecidos para órgãos públicos e para os programas de longa duração com transparência, eficiência, efetividade e dentro das normas legais da ordem democrática. Diante da importância deste conselho para a execução desta política pública, salientam-se as suas atribuições, definidas na Resolução 038/2009, conforme art. 27, na qual está previsto aos seus membros desempenhar as seguintes ações: 
I - acompanhar e fiscalizar o cumprimento do disposto nos arts. $2^{\circ}$ e $3^{\circ}$ desta Resolução; II - acompanhar e fiscalizar a aplicação dos recursos destinados à alimentação escolar; III zelar pela qualidade dos alimentos, em especial quanto às condições higiênicas, bem como à aceitabilidade dos cardápios oferecidos; IV - receber o Relatório Anual de Gestão do PNAE (anexo IX), conforme art. 34 e emitir parecer conclusivo acerca da aprovação ou não da execução do Programa. Compete, ainda, ao Conselho de Alimentação Escolar: I - comunicar ao FNDE, aos Tribunais de Contas, à Controladoria-Geral da União, ao Ministério Público e aos demais órgãos de controle qualquer irregularidade identificada na execução do PNAE, inclusive em relação ao apoio para funcionamento do CAE, sob pena de responsabilidade solidária de seus membros; II - fornecer informações e apresentar relatórios acerca do acompanhamento da execução do PNAE, sempre que solicitado; III - realizar reunião específica para apreciação da prestação de contas com a participação de, no mínimo, 2/3 (dois terços) dos conselheiros titulares; IV - elaborar o Regimento Interno, observando o disposto nesta Resolução (BRASIL, 2009, p. 15-16).

Nota-se, diante dessa Resolução, que os conselheiros podem constituir-se em uma efetiva representação da comunidade, desde que esses estejam comprometidos, sejam atuantes e representem os interesses coletivos da sociedade. Entretanto, ainda são tímidos os meios disponíveis na sociedade, além do despreparo do cidadão, como destacaremos a seguir. Entretanto, o controle social sobre o PNAE, traduzido pelo papel dos conselhos, reproduz um momento de relevante expressão política da sociedade, ao apoderar-se da complexa função de participar da gestão de uma política pública.

A Lei nº 13.990/2012 (artigos 41 e 42) prevê que os Conselhos Escolares, resguardados os princípios constitucionais, têm funções consultiva, deliberativa, executora e fiscalizadora nas questões pedagógico-administrativo-financeiras. Entre outras competências, deve elaborar seu próprio regimento, prestar contas sobre a movimentação financeira e divulgá-la, discutir o regimento escolar junto à direção e analisar os resultados da avaliação interna e externa, propondo melhorias para o desempenho da escola.

Segundo o documento Escola de Gestores, disponibilizado pelo Ministério da Educação,

O conselho escolar é um órgão de representação da comunidade escolar. Trata-se de uma instância colegiada que deve ser composta por representantes de todos os segmentos da comunidade escolar e constitui-se num espaço de discussão de caráter consultivo e/ou deliberativo. Ele não deve ser o único órgão de representação, mas aquele que congrega as diversas representações para se constituir em instrumento que, por sua natureza, criará as condições para a instauração de processos mais democráticos dentro da escola. Portanto, o conselho escolar deve ser fruto de um processo coerente e efetivo de construção coletiva. A configuração do conselho escolar varia entre os estados, entre os municípios e até mesmo entre as escolas. Assim, a quantidade de representantes eleitos, na maioria das vezes, depende do tamanho da escola, do número de classes e de estudantes que ela possui (BRASIL, 2009). 
Gadotti (1994) adverte que os conselhos escolares tendem a fracassar se instituídos somente como uma medida burocrática e isolada. "É necessário que estes órgãos visem, de fato, a democratização das decisões. Neste plano, sugere a autonomia para os movimentos sociais; abertura de canais de participação pela administração e a transparência administrativa, ou seja, democratização das informações" (1994, p. 6). Em outras palavras, é necessário que a população se inteire das informações para legitimar sua participação, conhecendo o funcionamento da administração e do orçamento, bem como as leis sob as quais se encontra a administração pública.

Por outro lado, as condições para que essa participação se efetive também precisam ocorrer, permitindo que os conselheiros possam participar dos encontros em locais convenientes e de fácil acesso, e em horários adequados para que se sintam confortáveis e prestigiados ao realizar o seu trabalho, desenvolvendo uma participação de alta intensidade, como afirma Santos (2000).

Nóbrega (2011, p. 151) salienta que, mesmo os conselhos escolares sendo um espaço de multiculturalidade, pluralismo de ideias e de participação democrática, são necessários ainda estudos sistemáticos sobre a relação entre teoria e prática.

Cada conselho tem suas peculiaridades e regulamentação própria, de acordo com o tamanho do município e da escola, mas, normalmente, constituem-se com uma representação de 50\% de funcionários da escola e 50\% de membros da comunidade local. Os encontros geralmente têm a periodicidade bimestral.

\section{A instituição conselhos: participação ou representatividade?}

Para entender e refletir sobre os conselhos escolares como espaços de prática participativa, buscamos a legislação referente à criação dessas instituições no município de Frederico Westphalen, RS, a qual descrevemos na sequência.

O município de Frederico Westphalen está localizado na região do Médio alto Uruguai, noroeste do estado do Rio Grande do Sul, com área territorial de 264.976 $\mathrm{km}^{2}$ e uma estimativa populacional de 30.251 habitantes, segundo dados do Instituto Brasileiro de Geografia e Estatística (IBGE) de 2013. Está distante $428 \mathrm{~km}$ da capital do estado, Porto Alegre. Destaca-se na região do médio alto Uruguai, sendo popularmente conhecido como a "Princesa do Médio Alto Uruguai", título conferido por meio da Lei Estadual no 13.801/2011. Em Frederico Westphalen, no ano de 2002, a Lei Municipal $\mathrm{n}^{\circ} 2.666$, de 7 de outubro do mesmo ano, estabeleceu a eleição direta para diretores nas escolas municipais, pela comunidade escolar. A lei municipal define comunidade escolar como o conjunto de alunos, pais ou responsáveis por alunos, membros do magistério e demais servidores públicos em efetivo exercício na unidade escolar. 
A Lei Municipal no 2.757/ 2003 dispõe sobre a Gestão Democrática do Ensino por intermédio de Conselhos Escolares, seguindo preceitos inscritos no artigo 206, inciso VI, da Constituição Federal de 1988 e no artigo 14, incisos I e II da Lei Federal no 9.394, de 20 de dezembro de 1996 - Lei de Diretrizes e Bases da Educação Nacional. No artigo $3^{\circ}$, a lei municipal estabelece como principais atribuições do conselho escolar: elaborar seu regimento; garantir a participação da comunidade na gestão escolar; avaliar os resultados do processo de ensino-aprendizagem e sugerir melhorias; elaborar e/ou alterar o regimento escolar; visar o aperfeiçoamento dos serviços educacionais; fiscalizar o cumprimento do calendário escolar; acompanhar a elaboração do Projeto Político-Pedagógico (PPP) da unidade escolar; fiscalizar a aplicação dos recursos, divulgar a prestação de contas trimestralmente e convocar assembleias gerais dos segmentos da comunidade escolar.

O órgão tem poderes para, inclusive, abrir sindicância em caso de apuração de irregularidades ocorridas no âmbito da unidade de ensino, comprovar alguma inadequação metodológica de docentes, e propor alternativas para a solução de problemas e impasses pedagógicos e administrativos. Sua composição abrange os seguintes membros: diretor da unidade de ensino (membro nato); dois docentes, um servidor do quadro geral, dois representantes dos pais ou responsáveis e um representante discente. Os membros do conselho são escolhidos por seus pares em assembleia e, para cada membro, há um suplente. O mandato é de dois anos, sendo permitida a reeleição por igual período. A periodicidade dos encontros do conselho escolar em Frederico Westphalen é mensal.

Dados do Ministério da Educação, que mantém um sistema on-line de Banco de Experiências de Conselhos por todo o país, apontam para mais de sessenta mil conselhos escolares distribuídos pelos 5.570 municípios brasileiros.

Essa análise partiu dos documentos sobre o conselho escolar, mas nem sempre um documento legal, regulatório, bem elaborado e com princípios democráticos pode estar sendo compreendido pelos membros. Um exemplo parte da investigação de Nóbrega (2011), que por meio de observações e entrevistas com os conselheiros escolares, constatou que, aproximadamente, metade dos conselheiros não tinha conhecimento da participação discente e do próprio estatuto da entidade, denotando dificuldade expressiva para compor a integração entre o saber e a ação prática. $\mathrm{O}$ autor aferiu que, no conselho de uma escola municipal no município de Solânea, no estado da Paraíba, 57\% dos membros desconhecia o regimento da escola e o regimento do próprio conselho. Além disso, somente $14 \%$ dos entrevistados citaram a participação estudantil. Sobre a periodicidade de reuniões ordinárias do conselho escolar, ainda segundo Nóbrega (2011), 57\% das entrevistadas responderam que são bimestrais e 43\%, que são semestrais, e 57\% admitiu que o órgão precisa me- 
lhorar a sua atuação. Observamos que existe uma discrepância entre os membros do conselho escolar com relação à compreensão de sua verdadeira função, gerando dúvidas, inclusive, sobre a efetividade do trabalho realizado.

O controle social relaciona-se intimamente com o processo e resultados da mobilização da sociedade na luta pela garantia dos direitos humanos e sociais. Cabe destacar que tal coesão, em geral, enfrenta as forças opostas da sociedade capitalista, dominadas pelo Estado e conduzida pelos detentores de capital. Vale dizer que o exercício da democracia torna-se limitado pelo poder econômico, que gera condições desiguais de poder. Nota-se que a maior participação da sociedade civil nos espaços de controle social de políticas públicas na área social é bem vista desde que não interfira nas políticas de investimento. Os grupos econômicos, com maior influência na direção do Estado, têm para si as "rédeas" da condução das políticas (PEDRINI; ADAMS; SILVA, 2007).

$\mathrm{Na}$ democracia liberal, todos são formalmente iguais para fins de representação política, isto é, a noção de igualdade que sustenta o sufrágio universal nesse modelo de democracia gera a ilusão de participação igualitária no sistema representativo e permite referendar o revezamento de dirigentes em benefício dos grupos no poder. Isso se confere na medida em que o sistema capitalista se desenvolve, acentuando-se as desigualdades sociais e restringindo sua participação.

Em uma perspectiva histórica do nosso país, a herança colonialista, patrimonialista e clientelista, combinada com a imposição de uma ditadura militar e econômica protagonizou um cenário submisso da sociedade, ficando cada vez mais refém de ações públicas compensatórias. Esta concepção provoca a reflexão a respeito dos entraves do exercício da democracia num país em que as contradições sociais crucialmente se acentuam. Portanto, surge a necessidade de as políticas públicas emergirem da sociedade civil, cujos problemas sociais tomam expressão no meio local.

Schlesener (2006) reafirma que os conselhos geraram grande expectativa no sentido de serem canais mediadores da democracia participativa. Porém, diante de limites, dificuldades e contradições aponta vários pontos negativos deste mecanismo de participação: os governos tem usado tal instância para legitimar suas políticas; atuação reduzida às reuniões com pouco ou nenhum diálogo com outros conselhos; reprodução da organização e participação nos moldes do Estado com divisões internas; disputa de interesses de projetos políticos; entidades se sentem na "dívida" com o prefeito que assinou determinado projeto que a favorecem. Aliado a esses obstáculos, encontramos ainda espaços profundamente suscetíveis aos jogos de poder estabelecidos entre as diversas forças ali representadas.

Embora necessária, não basta a eleição de conselheiros, desvinculada de outras medidas que transformem radicalmente a estrutura administrativa; não basta 
instituir um conselho com a participação de representantes da sociedade civil, professores, pais e executivo, mesmo com atribuições deliberativas, se a função política ficar inteiramente prejudicada pelas circunstâncias de que a autoridade máxima de um município e seus aliados não depende da hipotética deliberação desse conselho.

Aliado a essas dificuldades, Gohn (2011) cita outro problema enfrentado pelos conselhos:

De um lado, eles são formas de descentralização do poder - demandada pela população -, mas de outro, eles são fruto da crise das instituições públicas e parte constitutiva das reformas estatais que implicam diminuição de custos e transferência de responsabilidades na solução dos problemas locais para os cidadãos, tratados como usuários ou clientes dos serviços públicos (GOHN, 2011, p. 99).

De tal modo, para que o controle social se concretize a mobilização da sociedade civil organizada deve interferir na gestão pública. Isso pode ser viabilizado de forma coletiva, através da apropriação de processos, participação na deliberação, fiscalização das ações estatais, avaliação crítica, reorientando as ações e prioridades do Estado. Porém, a sua consolidação depende do ambiente democrático e de condições necessárias para a participação cidadã.

Os conselhos apresentam limitações, mas ainda assim, refere Lima, são canais legítimos de participação e precisam ser ocupados "por pessoas que concebam a si mesmas como sujeitos históricos, que são capazes de mudar e construir um conselho que garanta a participação, a democracia, a autonomia, em um sentido mais crítico, mais político" (2009, p. 485). Para evoluir nesta direção, torna-se necessário: maior espaço, visibilidade e protagonismo, criar estratégias de enfrentamento da arquitetura do Estado, enfrentamento da questão do financiamento das políticas públicas, articulação da ação dos conselhos com outras formas de controle social como audiências públicas, leis de iniciativa popular, plebiscito, ação civil pública, controles orçamentários, avanço de iniciativas na transparência de recursos públicos, cobrança dos gestores nas ações diversas políticas, olhar voltado para a população e garantia da autonomia destes órgãos.

O que se precisa, na verdade, é uma definição precisa das competências e atribuições dos conselhos. Deve haver uma especificação detalhada da atuação dos conselheiros. Além disso, é necessário incentivar e qualificar a população para que a participação realmente se efetive. Em vista disso, Gohn (2011) destaca: "É preciso entender o espaço da política para que se possa fiscalizar e também propor políticas; é preciso capacitação ampla que possibilite a todos os membros do conselho uma visão geral da política e da administração" (GOHN, 2011, p. 96).

Percebemos grandes dilemas enfrentados por este segmento, mediante a sua institucionalidade, seja pela forte influência da política neoliberal, seja pela desar- 
ticulação existente entre os conselhos e suas entidades representativas ou ainda pela falta de mobilização, dificultando ainda mais a atuação dos conselhos na esfera da participação social. Participar, portanto, representa influir nas decisões, controlando-as, e como conhecedores das especificidades da realidade local (e de suas necessidades) apresentar propostas e discuti-las, ao contrário de, verticalmente, aprovar ou não aprovar determinado item da pauta em uma reunião. Nesta perspectiva, Freire (2001) adverte que a gestão democrática é ato político que deve ser organizado coletivamente, dialogicamente, com o propósito de desenvolver ações que propiciem qualidade na escola.

Para que os conselheiros possam melhor desempenhar sua função, estados brasileiros já contam com alguns instrumentos à disposição para sua formação. Um exemplo são os cursos de formação para Conselheiros Escolares , de formato on-line, mantidos pelo Ministério da Educação, através do Programa Nacional de Fortalecimento dos Conselhos Escolares. Os cursos destinam-se aos profissionais técnicos da educação, da Secretaria Estadual, Centros Regionais de Educação e/ou Secretarias Municipais de Educação (e não diretamente às pessoas da comunidade escolar que integram os conselhos), como curso de extensão universitária, tendo como principal objetivo promover ações direcionadas aos conselhos escolares para formação e atualização dos conhecimentos necessários à implementação e consolidação do Programa. Estes funcionários do setor público, por sua vez, são responsáveis por multiplicar aos demais representantes da comunidade escolar o que aprenderam.

\section{Considerações finais}

A possibilidade de atuação dos conselhos como mecanismo de controle social é resultado do processo de democratização do país e pressuposto para a consolidação da democracia participativa. Assim, a sociedade tem, através dos seus conselheiros eleitos, a oportunidade de acompanhar, fiscalizar e contribuir para o controle dos recursos públicos repassados aos municípios e estados.

Não basta, porém, criar mecanismos de participação popular e de controle social das políticas públicas, é preciso atentar para a necessidade de criar, também, simultaneamente as condições de participação. A participação, para ser efetivada, precisa ser qualificada. Ela não deve ser algo paralelo, mas organizado, ativo e participativo, longe da "patologia da representantividade" sobre a qual nos alertam Santos e Avritzer (2002), como nos referíamos no princípio deste trabalho.

Os termos "participação", "controle social", "democracia" têm sido amplamente utilizados nos dias de hoje. Os programas governamentais apoderam-se de mecanismos de controle social para materializar esse sistema de governo. A exemplo 
dos conselhos, podemos considerá-lo um avanço conquistado pelos cidadãos, dada a tradição autoritária presente na história brasileira. Ao analisarmos estudos e práticas vivenciadas, podemos perceber que, apesar da apropriação dos termos, a herança deste período de repressão, aliada a influência exercida pelo capitalismo, impede sua efetiva implantação.

Por fim, os conselhos são inovações recentes, ainda não apropriadas pela população como espaços de participação, portanto, fazem-se necessários outros estudos, que busquem aprofundar esta temática e contribuir para o fortalecimento desses espaços, enquanto entes públicos de interesse da comunidade geral. Ainda assim, é possível perceber que caminhamos para um maior controle social local, já que os conselhos se configuram em uma ferramenta importante, ainda que representativa e não participativa de fato.

Segundo Freire (2001), somos seres da pergunta, da práxis, portanto não prontos. Apesar disso, a cultura do silêncio ainda retrai o cidadão, já que calar foi, até pouco tempo, o seu papel. Assim, o diálogo, potencializador da reflexão, do debate, da criticidade, do discernimento e da tomada de decisões é uma maneira ímpar de avanço nos processos democráticos, contribuindo para a construção da "humanidade do ser humano" (SOUZA, 2002, p. 154). É preciso, pois, deixar de lado a cultura do silêncio e partir para o diálogo, para a participação efetiva.

\section{The institution of boards: participation and social control, or "pathology" of representatitvity?}

\section{Abstract}

This essay, of a theoretical and bibliographical character, aims to investigate the role of school and feeding boards in Brazilian municipalities. Therefore, we analyzed the construction of the democratic process in Brazil, as well as the path of popular participation in these agencies, composed by school community representatives. Highlighting the city of Frederico Westphalen, Rio Grande do Sul and a study done in the state of Paraíba (NÓBREGA, 2011), tracing possibilities and challenges for participation even through the representative system. Great dilemmas faced by the boards that hinder the performance of this segment as a sphere of social participation were perceived, since many of these boards collide in the bureaucracy and lack of knowledge of their mission by its components. Despite the number of investigations about this being very scarce, it is possible to conclude it is necessary to strengthen the relationship between theory and practice for the school and feeding boards to be able to fulfill their role of bringing the community into the school more effectively, thus becoming an important tool for participation and emancipation. In this sense it is necessary to strengthen participation through the boards effective action and so achieve the exercise of citizenship.

Keywords: Democracy. Participation. Representativeness. Shool Boards. Feeding Boards. 


\section{Referências}

BAVA, Silvio Caccia. Democracia e participação. In: TEIXEIRA, Ana Claudia Chaves (Org.). Os sentidos da democracia e da participação. São Paulo: Instituto Pólis, 2005. p. 31-40. (Anais do Seminário “Os Sentidos da Democracia e da Participação”; São Paulo, jul. 2004).

BOBBIO, Norberto. O futuro da Democracia. Trad. Marco Aurélio Nogueia. 6. ed. Rio de Janeiro: Paz e Terra, 1986. (Coleção Pensamento Crítico, v. 63).

BOBBIO, Norberto; MATTEUCCI, Nicola; PASQUINO, Gianfranco. Dicionário de política. Trad. Carmen C. Varriale et al. Brasília: Editora Universidade de Brasília, 1998.

BRASIL. Resolução FNDE/CD nº 38, de 16 de julho de 2009. Dispõe sobre o atendimento da alimentação escolar aos alunos da educação básica no Programa Nacional de Alimentação Escolar - PNAE. Fundo Nacional de Desenvolvimento da Educação, Conselho Deliberativo, Brasília, DF, 2009 .

BRAVO, Maria Inês Souza; CORREIA, Maria Valéria Costa. Desafios do controle social na atualidade. Serviço Social \& Sociedade, São Paulo, n. 109, p. 126-150, jan./mar. 2012.

FAUNDEZ, Antonio. O poder da participação. São Paulo: Cortez, 1993.

FÁVERO, Altair Alberto; TONIETTO, Carina. A reconstrução da experiência democrática - a democracia como credo pedagógico na filosofia de Dewey. Revista Práxis Educativa, v. 7, n. 1, p. 179-197, jan./jun. 2012. Disponível em: <http://www.revistas2.uepg.br/index.php/praxiseducativa>. Acesso em: 2 mar. 2015.

FREIRE, Paulo. Política e educação. 5. ed. São Paulo: Cortez, 2001.

FURTADO, Celso. Brasil: da República oligárquica ao Estado militar. In: FURTADO, C. (Coord.). Brasil: tempos modernos. 3. ed. Rio de Janeiro: Paz e Terra, 1979.

GADOTTI, Moacir. Gestão democrática com participação popular no planejamento e na organização da educação nacional. 2013. CONAE. Disponível em: <http://conae2014.mec.gov.br/images/ pdf/artigogadotti_final.pdf>. Acesso em: 21 dez. 2014.

GADOTTI, Moacir. Escola Pública Popular: Educação Popular e Políticas Públicas no Brasil. In: INTERNATIONAL CONGRESS LATIN AMERICAN STUDIES ASSOCIATION, 18, 1994, Atlanta, Georgia. Anais... Atlanta, 1994. Disponível em: <http://www.plataformademocratica. org/Publicacoes/7065_Cached.pdf>. Acesso em: 2 dez. 2014.

GOHN, Maria da Glória. Conselhos gestores e participação sociopolítica. 4. ed. São Paulo: Cortez, 2011.

GOMES, Eduardo Granha Magalhães. Conselhos Gestores de Políticas Públicas: Democracia, Controle Social e Instituições. 2003. 110 f. Dissertação (Mestrado em Administração Pública) Fundação Getúlio Vargas, Escola de Administração de Empresas de São Paulo, São Paulo, 2003.

FREDERICO WESTPHALEN. Lei Municipal no 2.757, de 17 de setembro de 2003. Dispõe sobre a gestão democrática de ensino através de conselhos escolares. Prefeitura Municipal de Frederico Westphalen, RS, Brasil, 2003. 
LIMA, Antonio Bosco de. Estado, educação e controle social: introduzindo o tema. $R B P A E$, Porto ALegre, v. 25, p. 473-488, set.-dez. 2009. Disponívem em: <http://seer.ufrgs.br/index.php/rbpae/ article/view/19661/11459>. Acesso em: 2 dez. 2014.

NÓBREGA, Joselito Eulâmpio da Nóbrega et al. Conselho escolar, da teoria à prática: diagnóstico de atuação. 2012. Disponível em: <http://www.ies.ufpb.br/ojs2/index.php/rle/article/view/10970>. Acesso em: 6 dez. 2015.

PEDRINI, Dalila; ADAMS, Telo; SILVA, Vini Rabassa da. Controle social e fortalecimento da democracia participativa: dilemas e perspectivas. In: PEDRI, Maria Dalila, et AL. (Org.). Controle social de políticas públicas: caminhos, descobertas e desafios. São Paulo: Paulus, 2007. p. 21-47

SANTOS, Boaventura de Sousa. A Crítica da Razão Indolente: Contra o Desperdício da Experiência. 7. ed. São Paulo: Editora Cortez, 2000.

SANTOS, Boaventura de Sousa; AVRITZER, Leonardo. Para ampliar o cânone democrático. In: SANTOS, Boaventura de Sousa (Org.). Democratizar a Democracia. Os caminhos da democracia participativa. Porto: Edições Afrontamento, 2002. p. 39-82

SCHLESENER, Anita Helena. Gestão democrática da educação e formação dos conselhos escolares. In: FERREIRA, Naura S. Carapeto (Org.). Políticas públicas e gestão da educação: polêmicas, fundamentos e análises. Brasília: Líber Livro, 2006, p. 117-189.

SOUZA, João Francisco de. Atualidade de Paulo Freire: contribuições ao debate sobre a educação na diversidade cultural. Biblioteca freireana, v. 3. São Paulo: Cortez, 2002. 